Article

\title{
One-Dimensional Modelling of a Trilateral Flash Cycle System with Two-Phase Twin-Screw Expanders for Industrial Low-Grade Heat to Power Conversion
}

\author{
Giuseppe Bianchi ${ }^{1, * \mathbb{D}}$, Matteo Marchionni ${ }^{1}$, Stuart Kennedy ${ }^{2}$, Jeremy Miller ${ }^{3}$ and \\ Savvas Tassou ${ }^{1}$ (D) \\ 1 Institute of Energy Futures, RCUK Centre for Sustainable Energy use in Food chains (CSEF), Brunel \\ University London, Uxbridge UB8 3PH, UK \\ 2 Howden Compressors Ltd., Renfrew PA4 8XJ, UK \\ 3 Spirax Sarco Engineering PLC., Cheltenham GL51 9NQ, UK \\ * Correspondence: giuseppe.bianchi@brunel.ac.uk; Tel.: +44-1895-267707
}

Received: 30 May 2019; Accepted: 26 July 2019; Published: 29 July 2019

\begin{abstract}
This paper provides an overview of a one-dimensional modelling methodology for equipment and systems for heat to power conversion based on a staggered grid space discretization and implemented in the commercial software GT-SUITE ${ }^{\circledR}$. Particular attention is given to a newly developed modelling procedure for twin-screw machines that is based on a chamber modelling approach and considers leakage paths between cells and with the casing. This methodology is then applied to a low-grade heat to power conversion system based on a Trilateral Flash Cycle (TFC) equipped with two parallel two-phase twin-screw expanders and a control valve upstream of the machines to adapt the fluid quality for an optimal expander operation. The standalone expander model is used to generate performance maps of the machine, which serve as inputs for the TFC system model. Parametric analyses are eventually carried out to assess the impact of several operating parameters of the TFC unit on the recovered power and cycle thermal efficiency. The study shows that the most influencing factors on the TFC system's performance are the inlet temperature of the heat source and the expander speed. While the first depends on the topping industrial process, the expander speed can be used to optimize and control the TFC system operation also in transient or off-design operating conditions.
\end{abstract}

Keywords: one-dimensional modelling; GT-SUITE ${ }^{\circledR}$; energy conversion; positive displacement machine

\section{Introduction}

The use of numerical simulations to support the design activities of engineers and researchers has been constantly increasing over the years. A numerical model indeed frames a simplified version of the reality in a "digital twin", a powerful tool to develop and test new ideas without the same commitment of resources and time that such trials would require if done experimentally. Significant progress in numerical methodologies, exponential growth in computing power, and dramatic cost reduction for computing hardware have been the three major drivers for the success of numerical simulation in industry and research [1]. In particular, the availability of more computing power, envisaged by the well-known Moore's law, has led to more complicated numerical problems both in terms of size and formulation. For instance, in the field of Computational Fluid Dynamics (CFD), modelling techniques for turbulent flows have evolved from empirical correlations to a direct solution of the Navier-Stokes equations (DNS). Furthermore, today, multi-physics simulations are feasible. Among them, fluid-structure interaction (FSI) allows a two-way coupling between the deformation 
of the physical structure due to the flow, as well as a change of flow topology due to the change of structure. Another trend noticed with the increase of computing power is the greater complexity of the simulations. Indeed, if in the early days two-dimensional wings were analyzed [2], today, CFD on the full aircraft allows an understanding of the interactions between different parts of a system [3].

Notwithstanding the increase of cheap computational power, model developers and simulation engineers still have to balance the complexity, time, and cost of their calculations. For these reasons, the lower order models that have been developed in the past are still highly beneficial for today's simulations. For instance, in the analysis of a lubricated positive displacement compressor, one could think of doing transient CFD studies to investigate the air and oil flows throughout the machine, including coolers, filters, etc. [4]. This approach is theoretically feasible but would require a substantial investment in resources with limited additional outcomes than more simplified simulation approaches. Similarly, for optimization and control purposes, models must be light and quick enough to be recalled several times.

In this work, a one-dimensional modelling methodology developed in the software environment GT-SUITE ${ }^{\circledR}$ is presented. After a brief overview on the modelling theory, a test case related to a low-grade heat to power conversion system is discussed. In particular, the model of a two-phase twin-screw expander is recalled and eventually integrated in the system model, which performs a series of thermodynamic transformations according to a Trilateral Flash Cycle (TFC), an alternative variant to the Organic Rankine Cycle (ORC).

Despite the fact that ORC systems have been successfully applied for large scale heat sources in the medium-low temperature range (i.e., between $100^{\circ} \mathrm{C}$ and $300^{\circ} \mathrm{C}[5]$ ), as well as for lower power scales [6], TFC systems are characterized by a higher exergy efficiency and superior power output [7]. On the other hand, greater equipment is needed (i.e., heat exchangers) to handle larger volumetric flow rates of working fluid [8], and the technical aspects of the two-phase expansion have not been fully addressed yet. In particular, to fill this gap, several studies on screw machines have been carried out to assess different aspect as optimization [9], leakage [10] and suction, and discharge phenomena [11,12], which, however, require the development of complex models whose validity usually holds only for the particular component considered.

With respect to the literature, which considers ad-hoc modelling approaches tailored on the machines [13], the novel aspects of the research herein presented are the modelling methodology for the twin-screw expander, which is also applicable to air and refrigeration compressors, pumps, superchargers, etc. Moreover, the complex modelling of the TFC system has allowed it to perform holistic considerations that a standalone expander model would have prevented. These integration issues are highly significant to ensure that the design specifics for the expander are the ones provided by the TFC loop.

\section{Modelling Theory}

The commercial software GT-SUITE ${ }^{\mathrm{TM}}$ is based on a one-dimensional formulation of Navier-Stokes equations and on a staggered grid spatial discretization. According to this approach, and with reference to Figure 1, each system is discretized into a series of capacities such that manifolds are represented by single volumes while pipes are divided into one or more volumes. These volumes are eventually connected by boundaries. The scalar variables (pressure, temperature, density, internal energy, enthalpy, etc.) are assumed to be uniform in each volume. On the other hand, vector variables (mass flux, velocity, mass fraction fluxes, etc.) are calculated for each boundary. 


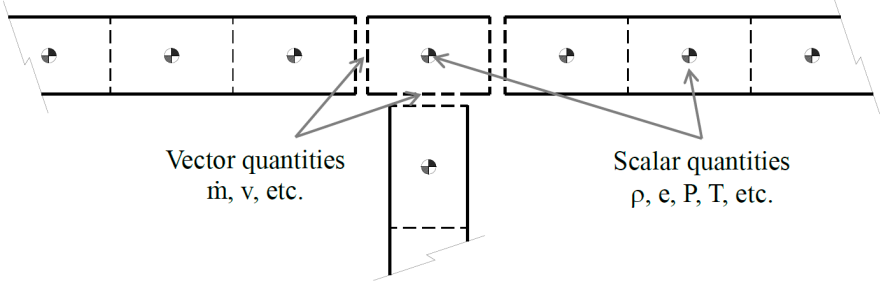

Figure 1. One-dimensional staggered grid formulation (courtesy of Gamma Technologies) [1].

The continuity equation (1) in a given capacity takes into account the algebraic sum of all the inflow and outflow contributions from the neighboring capacities that occur through the boundaries that characterize the reference element [14]:

$$
\frac{d m}{d t}=\sum_{i=1}^{B} \dot{m}_{i}
$$

The momentum equation (2) neglects body forces and takes into account the algebraic sum of momentums through the boundaries, pressure forces, and dissipations due to friction and pressure drops [14]. In pipes, the latter two terms are respectively related to distributed (i.e., due to surface finish) or concentrated (i.e., due to bends) pressure losses:

$$
\frac{d \dot{m}}{d t}=\frac{1}{d \zeta}\left(\sum_{i=1}^{B}\left(\dot{m}_{i} u_{i}\right)+d p A-4 C_{f} \frac{\rho u|u|}{2} \frac{d \zeta A}{D}-K_{p}\left(\frac{1}{2} \rho u|u|\right) A\right) .
$$

The energy Equation (3) states the conservation of total internal energy, i.e., the sum of internal energy and kinetic energy [14]. This formulation applies when using the explicit solver, as in the case of standalone machines. On the other hand, in the solution of circuits, an implicit solver is used and the energy equation becomes an enthalpy balance. Neglecting variations of potential energy, for a given capacity, the rate of change of total internal energy depends on the volume capacity variations, on the enthalpy fluxes and on heat transfer phenomena. The first term on the right-hand side of Equation (3) relates to the cell volume, so it is of paramount importance in positive displacement machines:

$$
\frac{d(m e)}{d t}=-p \frac{d V}{d t}+\sum_{i=1}^{B}\left(\dot{m}_{i}\left(e_{i}+\frac{p_{i}}{\rho_{i}}\right)\right)-H A_{s}\left(T_{\text {fluid }}-T_{\text {wall }}\right) \text {. }
$$

When the conservation equations are solved through an explicit method, a fifth order Runge-Kutta integration scheme is usually employed. With this approach, the primary solution variables are mass flow rate, density, and internal energy. In particular, to calculate mass and energy in a given volume at the following time step (that needs to satisfy the Courant condition for numerical stability), continuity and energy equations are firstly used and involve the reference volume and its neighbors. With the volume and mass known, the density is calculated, yielding density and energy.

Using a dynamic-link library (DLL) of the NIST REFPROP database [15] embedded in the software package, the solver iterates on pressure and temperature until they satisfy the density and energy already calculated for this time step.

\section{Modelling of Energy Conversion Systems Based on Bottoming Thermodynamic Cycles}

A typical energy conversion system based on thermodynamic cycles includes, in its simplest form, two heat exchangers, to reject and adsorb thermal power to and from external sources; two machines, a pump to pressurize the working fluid and an expansion device to convert its thermal energy into mechanical power; tanks, to prevent pump cavitation and the working fluid thermal expansion during transients; and a series of pipes and valves to connect all the system components. All these devices 
can be separately modelled and calibrated in GT-SUITE ${ }^{\circledR}$ by using data obtained from more complex models or experimental tests. Afterwards, the different components can be linked together to form the model of the whole energy conversion system.

\subsection{Modelling of Dynamic and Positive Displacement Machines}

GT-SUITE ${ }^{\circledR}$ allows the modelling of machines in different ways depending on the operating principle. In particular, for dynamic machines, such as centrifugal pumps, fans, and turbines, a map-based approach is considered. As such, the user will need to input data either from experiments or from more detailed models [16]. As an example, Figure 2 reports two performance maps related to a centrifugal ORC pump and a radial turbo-expander (not used in this study) [16].

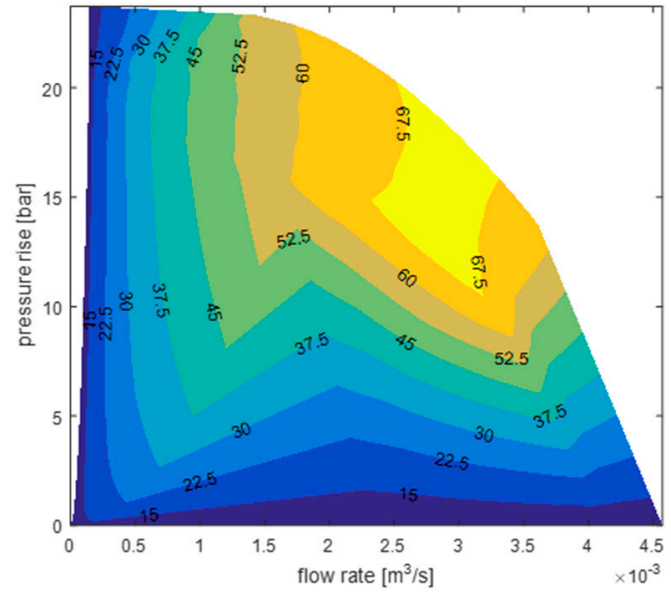

(a)

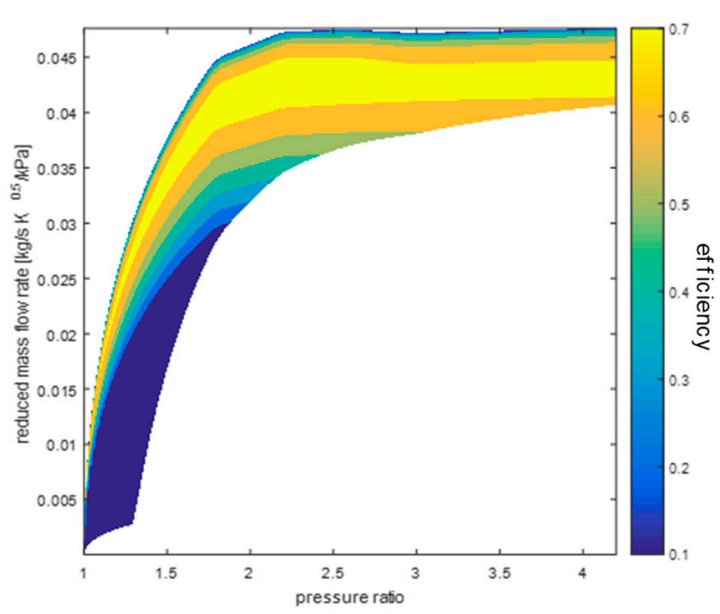

(b)

Figure 2. Performance maps used as inputs for models of dynamic machines: (a) efficiency map of a centrifugal pump for heat to power applications based on Organic Rankine Cycles (ORC); (b) Turbine total-static efficiency map of a radial ORC turbo-expander [16].

Positive displacement machines are modelled using a lumped parameter approach for fixed and variable capacities. Ducts are instead modelled with the 1D formulation recalled in Section 2. The chamber model available in the software is a general one. Hence, there is no formal difference between the simulation of a vane expander and that of scroll pump. For this reason, reference is here made to a twin-screw TFC expander, whose scheme is reported in Figure 3.

Once discretized, in the inlet and outlet pipes, the scalar equations (mass, energy) are solved at the centers of finite volumes, and the vector (mass flow) at the boundaries between them. The intake and exhaust manifolds are modeled as capacities of finite volume and connect the pipes with the filling and emptying expander cells, respectively. These components are named "flowsplits" and have multiple openings whose number depends on the number of cells and of the leakage paths. The solution of the flowsplit is similar to the pipe. The scalars are solved at the center of the volume, while the solution of the momentum equation is carried out separately at each of the volume openings (boundaries). In particular, the intake process is modelled with reference to the intake manifold shown in Figure 3 as control volume. The inlet flow is the one coming from the inlet pipe of the expander while the outlet flows are the ones that periodically fill the expander cells. Heat losses are here neglected. The governing equations are the ones presented in Section 2.

The expander cells that are physically generated when male and female rotor lobes engage are treated as capacities with uniform properties, and whose volume varies according to a law that is given as the input of the calculation. 


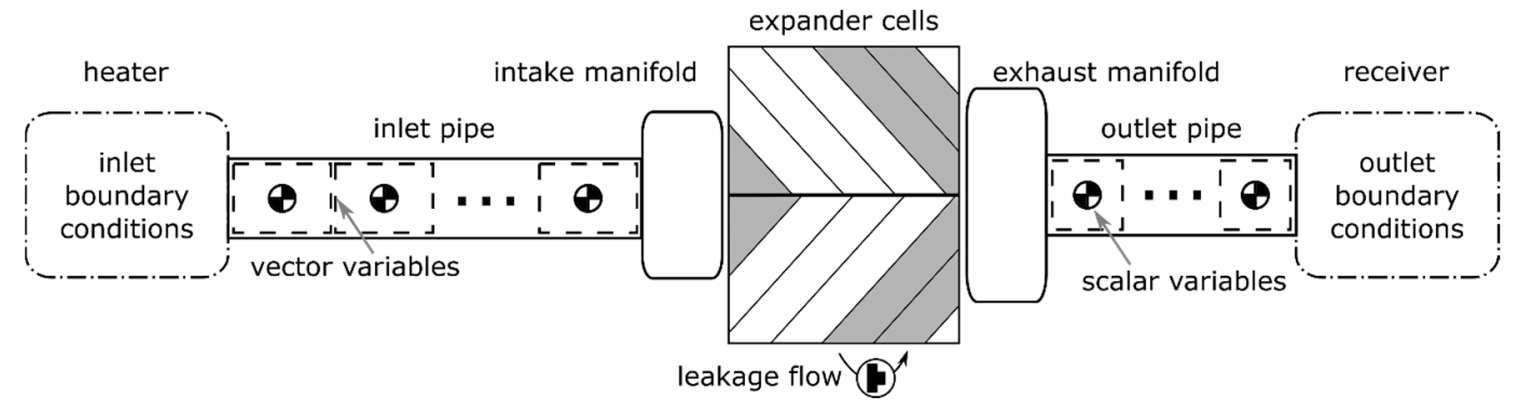

Figure 3. Modelling scheme for a twin-screw machine.

The angular evolutions of cell volume, suction, and discharge areas, as well as leakage paths are key information for the modelling of positive displacement machines. These inputs derive from a geometrical preprocessor that allows the analytical calculation of these quantities based on fundamental features of the machine, for instance, the one available in the commercial software SCORG ${ }^{\circledR}$. The same information can be also retrieved through CAD measurements. The modelling methodology developed by the Authors in [17] has been now implemented in SCORG ${ }^{\circledR}$ and GT-SUITE ${ }^{\circledR}$ through an interface that allows an easier workflow. Table 1 summarizes the main geometrical features of the twin-screw expander while Figure 4 reports the angular trends required for setting up the simulation.

Table 1. Main geometrical and operating data of modelled expander (courtesy of Howden Compressors Ltd.).

\begin{tabular}{cccc}
\hline Rotor Diameter & $\mathbf{2 0 4 . 0 ~} \mathbf{~ m m}$ & Built-In Volume Ratio & $\mathbf{5 . 0}$ \\
\hline Aspect ratio (L/D) & 1.93 & Suction/discharge ports & axial/axial \\
Male/female rotor lobes & $4 / 6$ & Revolution speed range & 1500-6000 RPM \\
Male rotor lead length & $405.0 \mathrm{~mm}$ & Tip speed range & $16-64 \mathrm{~m} / \mathrm{s}$ \\
Female rotor lead length & $607.5 \mathrm{~mm}$ & Weight & $887 \mathrm{~kg}$ \\
\hline
\end{tabular}

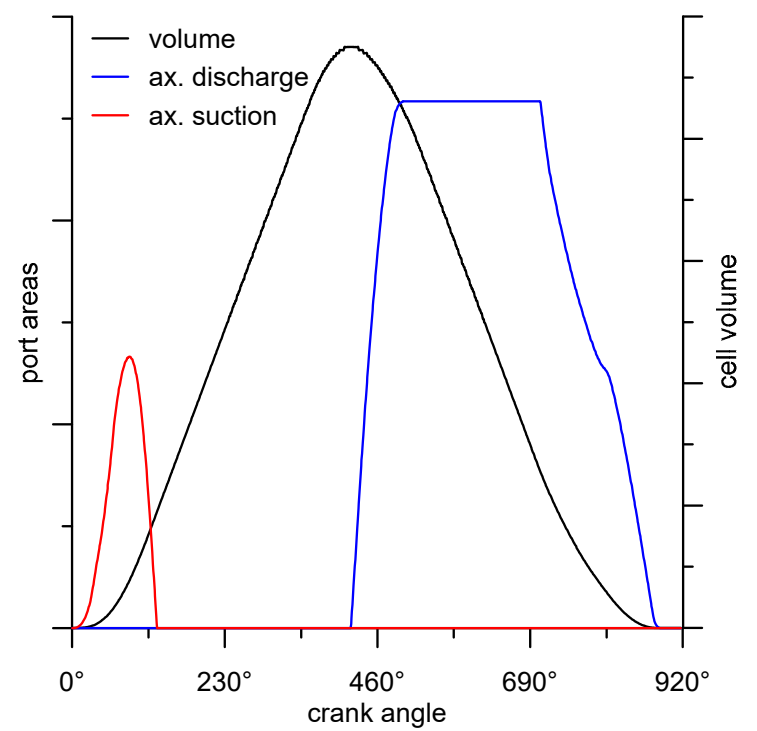

(a)

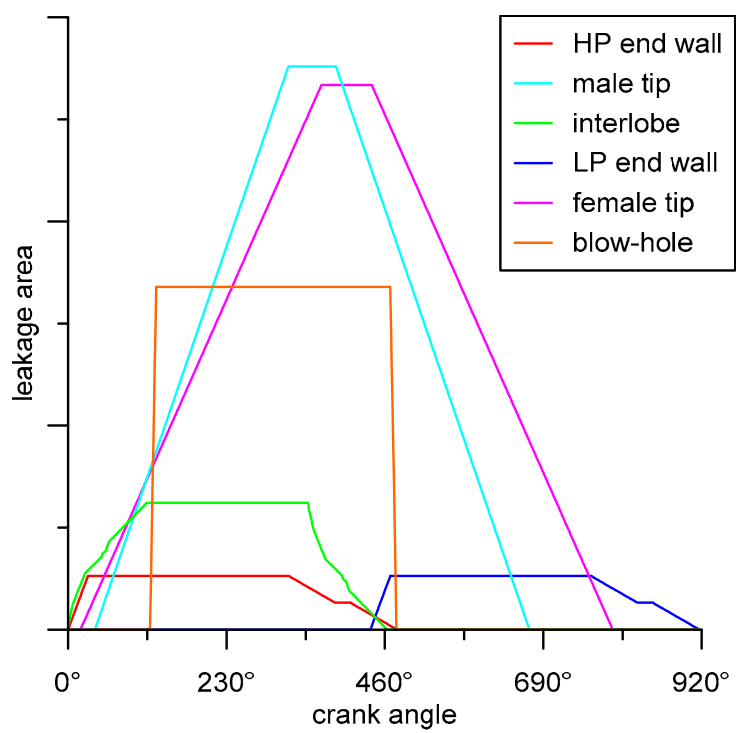

(b)

Figure 4. Geometrical input data for chamber modelling: (a) cell volume and ports areas; (b) leakage paths with reference to Figure 5 (courtesy of Howden Compressors Ltd.).

In positive displacement machines, the cycle duration of a cell is usually a sub-multiple of $360^{\circ}$. For instance, in a four-vane pump, the duration of a cycle requires $90^{\circ}$ to complete. On the other hand, in twin-screw machines, depending on the geometrical feature of the rotors, the cycle duration is not 
a sub-multiple of $360^{\circ}$. In the current case, as shown in Figure 4, the angular cycle duration of the twin-screw expander cell is $917^{\circ}$. Since GT-SUITE ${ }^{\circledR}$ does not accept angular inputs different from $360^{\circ}$ or $720^{\circ}$, to make the simulation of twin-screw machines possible, a scaling factor needs to be introduced. In particular, with reference to Equation (4), the number of cells in a twin-screw machine is the next integer (ceiling function) of the ratio between the real cell duration $\left(\Delta \alpha=917^{\circ}\right)$ multiplied by the number of male rotor lobes $\left(Z_{\text {male }}=4\right)$ and $360^{\circ}$. Therefore, the number of simulated cells $Z_{\text {sim }}$ is equal to 10 in the current case. To ensure the same volumetric flow rate, the inverse of the scaling factor becomes a correction factor for the revolution speed. An extensive explanation of the approach here outlined is reported in [17]:

$$
Z_{\text {sim }}=\operatorname{ceil}\left(\frac{\Delta \alpha Z_{\text {male }}}{360}\right) \text {. }
$$

The different leakage paths identified in Figure 5 are modelled as orifices whose equivalent areas show the angular trends reported in Figure $4 \mathrm{~b}$. Depending on the flow regimes, different formulations are used to model the leakage flow, namely the Bernoulli equation for liquids (not used in the current study) and the isentropic nozzle relationships for gases in subsonic and chocked conditions.

Two-phase flows are treated as gases having a specific heat equal to the weighted average, based on quality, of the specific heats of the saturated liquid and vapor states. Further details on the methodology and correlations are reported in $[14,17]$.

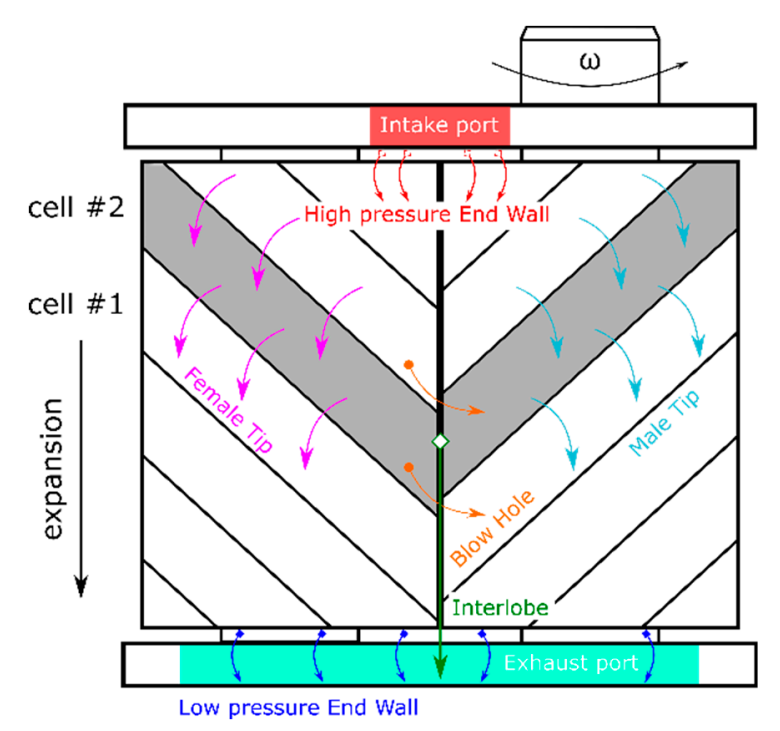

Figure 5. Leakage paths in a twin-screw machine.

\subsection{Heat Exchangers}

Depending on the geometry specified, the software builds an equivalent one-dimensional heat transfer network for the hot and the cold side of the heat exchanger, which are discretized along the flow path in a specific number of sub-volumes set by the user. The example shown in Figure 6 relates to Plate Heat Exchangers (PHE), which is a typical technology for energy conversion systems that do not involve exhausts. The hot and the cold sides of the PHE are considered as a series of interconnected pipes whose hydraulic diameter and wetted perimeter are equal to the ones of the heat exchanger flow passages (i.e., flow channel between two plates). The metallic part of the PHE is also discretized as a series thermal masses linked through convective connections to the pipes sub-models. These thermal masses account for the thermal inertia of the heat exchanger wall by considering the material properties of the metal composing the device. 
The staggered approach described in Section 2 is, therefore, applied to each sub-volume to calculate the pressure and the main thermodynamic quantities at their boundaries. In particular, the modelling methodology requires both performance data and the geometrical features of the device as inputs. This information can be inserted with reference to templates, as in the case of PHE, or even using the actual CAD model of the heat exchanger. To characterize instead the performance of the heat exchanger, data referring to different operating points of the device at design and off-design conditions can be used. In particular, the inputs required are the mass flow rates, the inlet temperatures, and the inlet and outlet pressures of hot and cold flows. These data are used to calculate the best fitting coefficients of Nusselt-Reynolds correlations that are used in the heat transfer calculation along the equivalent one-dimensional passages, with whom the heat exchanger channels are approximated.

With reference to PHE, pressure drops across the heat exchanger are calculated through an approximation of the Colebrook equation proposed by Serghides [18]. On the other hand, the Dittus-Boelter correlation is used in single phase heat transfer [19], while in the two-phase region the correlation from Yan et al. [20] and the one from Donowsky and Kandlikar [21] are used to model condensation and vaporisation respectively. It is worth mentioning that even though the correlation from Yan et al. was developed for R134a, later studies on plate heat exchangers using R245fa used this correlation as baseline [22].

In the current study, the heat transfer and pressure drop correlations have been calibrated against performance data provided by the manufacturer of the PHEs in 10 operating conditions where mass flow rates, inlet pressures and inlet temperatures of the hot and cold streams were varied.
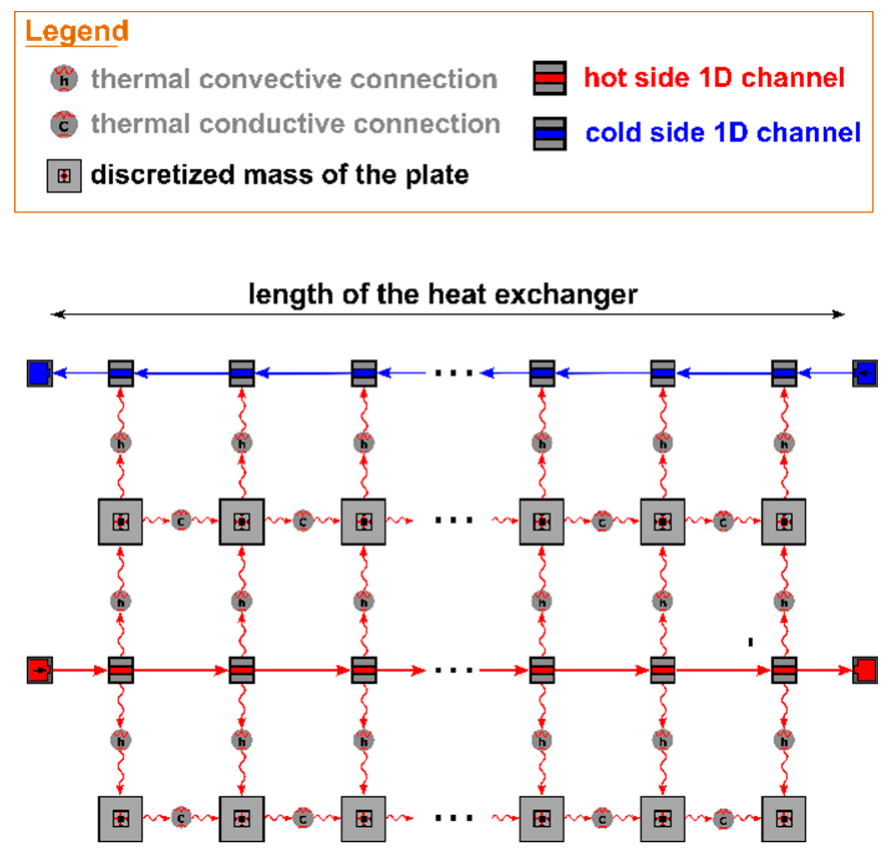

Figure 6. 1D heat transfer network.

\subsection{Pipes, Valves, and System Auxiliaries}

Straight pipes or bends are also treated with the staggered approach described in Section 2. To model the heat transfer through the external environment, a different heat loss model or customized heat transfer correlations can be used. Distributed pressure drops are instead calculated knowing the material properties of the tube material, including the surface roughness, as well as the pressure loss model or correlation considered. This approach has been adopted also for the current study. 
The valves, on the other hand, can be considered as a look-up table, inserting as input their flow characteristic (the flow coefficient as a function of the pressure difference across the device), or more detailed models, which consider the device geometry and dynamics. In the current study, the valve opening was taken into account through the diameter of the cross section, which could vary from the pipe diameter $(130 \mathrm{~mm})$ to nearly one third of the maximum cross section $(40 \mathrm{~mm})$. Hence, the opening varied from $100 \%$ to $9 \%$ of the full flow passage.

Finally, receivers or tanks can be modelled using available templates, which require only the device volume and the initial phase composition of the fluid contained, or they can be customized by means of a CAD tool and consequently imported in the software platform as an equivalent one-dimensional series of discretized volumes. In the current case, the receiver was modelled using only the volume of the tank as input data, i.e., the simplest approach.

\section{Results and Discussion}

The reference test case relates to a low-grade heat to power conversion system from a tire press exhaust. The energy recovery unit has been designed based on a bottoming Trilateral Flash Cycle; the first law analysis and the working fluid selection is presented in [23]. The theoretical system performance, i.e., the one resulting from the cycle analysis carried out in [23], are summarized in Table 2, where the net power output is the difference between expansion and pumping powers while the cycle thermal efficiency is the ratio between net power output and the heat gain, all of them expressed as absolute enthalpy differences. The working fluid at the end of the heat recovery phase was assumed to be in saturated liquid conditions. This fact motivates why this study relates to a Trilateral Flash Cycle rather than an Organic Rankine Cycle, while the full or partial vaporization to the working fluid takes place.

Table 2. Results from the cycle analysis at design point [18].

\begin{tabular}{cccc}
\hline & Hot Water & R245fa & Cold Water \\
\hline Mass flow rate $(\mathrm{kg} / \mathrm{s})$ & 7.84 & 25.34 & 89.56 \\
Inlet/Max pres (bar) & 4.0 & 7.2 & 4.0 \\
Outlet/Min pres (bar) & 3.5 & 1.2 & 4.0 \\
Inlet/Min temp $\left({ }^{\circ} \mathrm{C}\right)$ & 85.0 & 19.0 & 12.0 \\
Outlet/Max temp $\left({ }^{\circ} \mathrm{C}\right)$ & 24.0 & 76.5 & 17.0 \\
Expander isentropic eff. & & $75 \%$ & \\
Net power output $(\mathrm{kW})$ & & $129 \mathrm{~kW}$ & \\
Cycle thermal efficiency & & $6.4 \%$ & \\
\hline
\end{tabular}

Figure 7 shows the model block diagram of the TFC system, which is composed of a centrifugal pump, two twin-screw expanders operating in parallel, and plate heat exchangers having R245fa as working fluid and water streams as heat source and sink. The reason for using two expanders in parallel related to the lack of machinery with a size capable to deal with the large mass flow rate of the organic fluid. Furthermore, a control valve upstream of the expanders was considered to optimize the fluid quality for a correct intake through the suction port. 


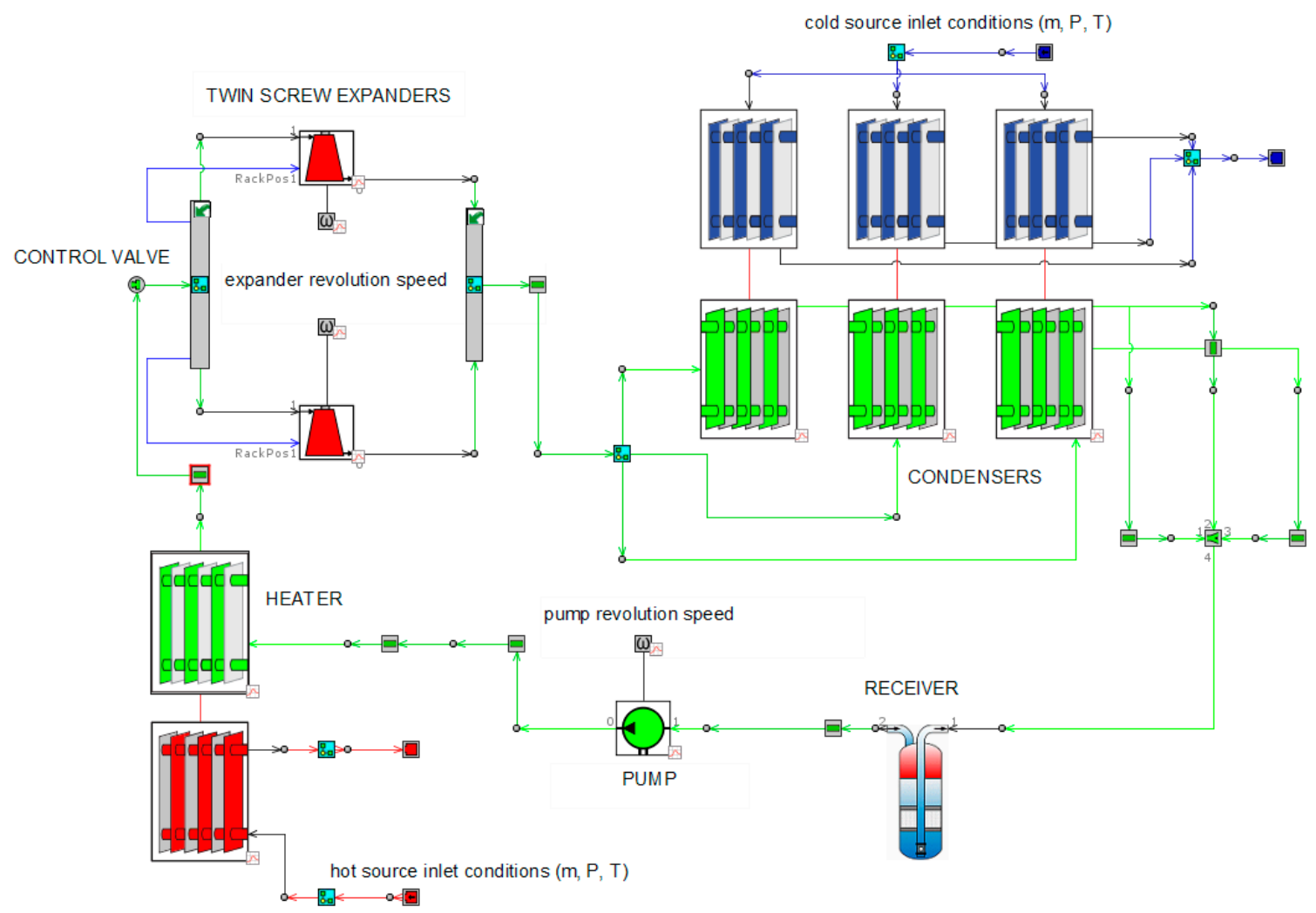

Figure 7. Trilateral Flash Cycle (TFC) model scheme developed in GT-SUITE ${ }^{\circledR}$.

\subsection{Twin-Screw Two-Phase Expander}

With reference to the data listed in Table 1 and the methodology reported in paragraph 3.1, the expander was modelled as a 10-cell positive displacement machine, where the number of cells results from Equation (4). The expander model block diagram is displayed in Figure 8 and shows the intake and exhaust manifolds interacting with the expander cells but also the different leakage paths. The boundary conditions for the simulations were the revolution speed, the pressures across the machine, and the inlet quality.

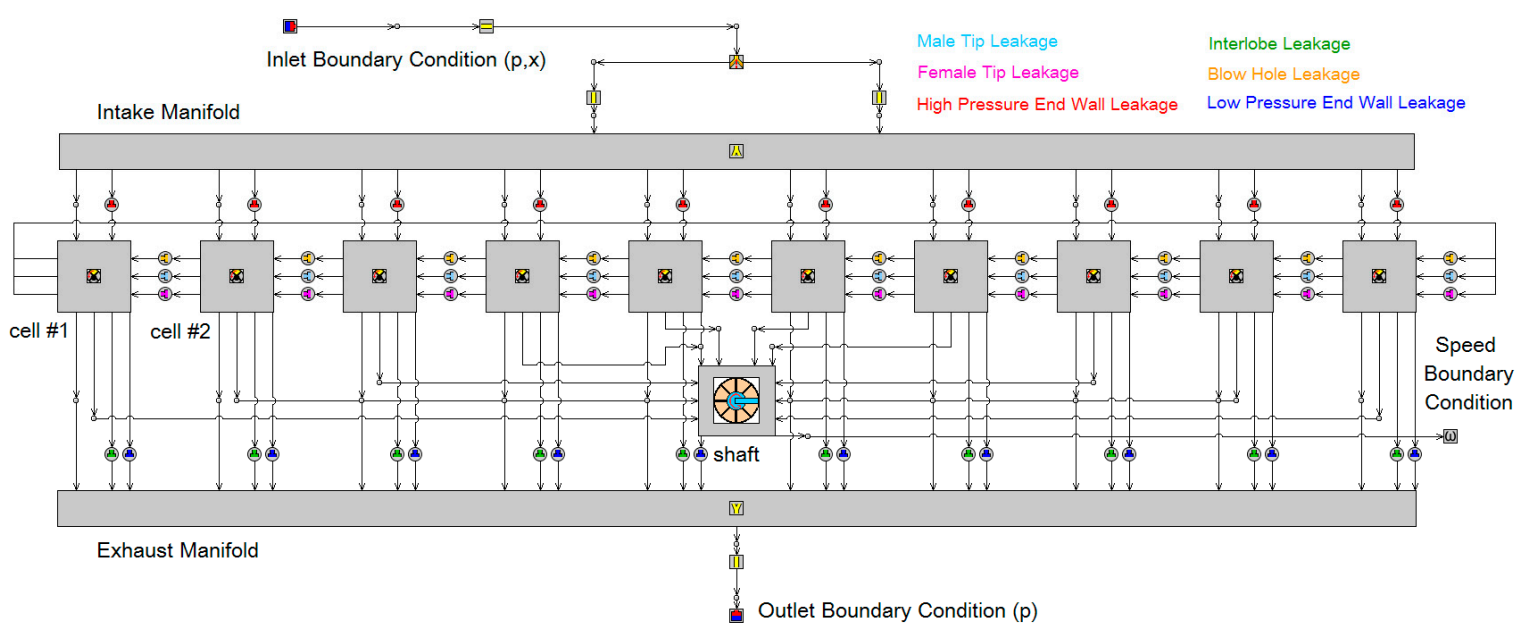

Figure 8. Twin-screw expander model block diagram (data refer to Table 1).

Although the model is capable of extracting detailed information about the expander operation as the indicator and quality diagrams, for the sake of the study, the results here presented focus on the 
expander performance maps since this information was eventually used as input data for the TFC system simulations. A suggested reference for detailed expander results is [17].

The performance maps shown in Figure 9 refer to a constant manometric pressure ratio across the machine and report the effect of inlet quality and revolution speed on the expander performance in terms of mass flow rate (Figure 9a) and power output (Figure 9b). Inlet and outlet pressure boundary conditions are the ones showed in Table 2. This simulation setup does not constrain the mass flow rate required by the expander; on the other hand, in the TFC system simulations reported in paragraph 4.2, there is a strict interaction between the mass flow rate supplied by the pump and the one required by the expander. Matching these two mass flow rates is essential to ensure an operation of the heat to power conversion unit at design conditions.

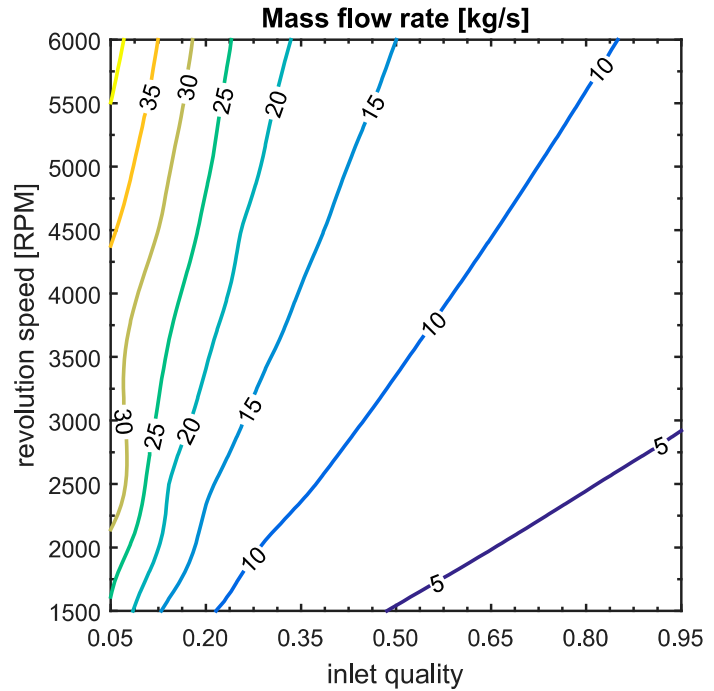

(a)

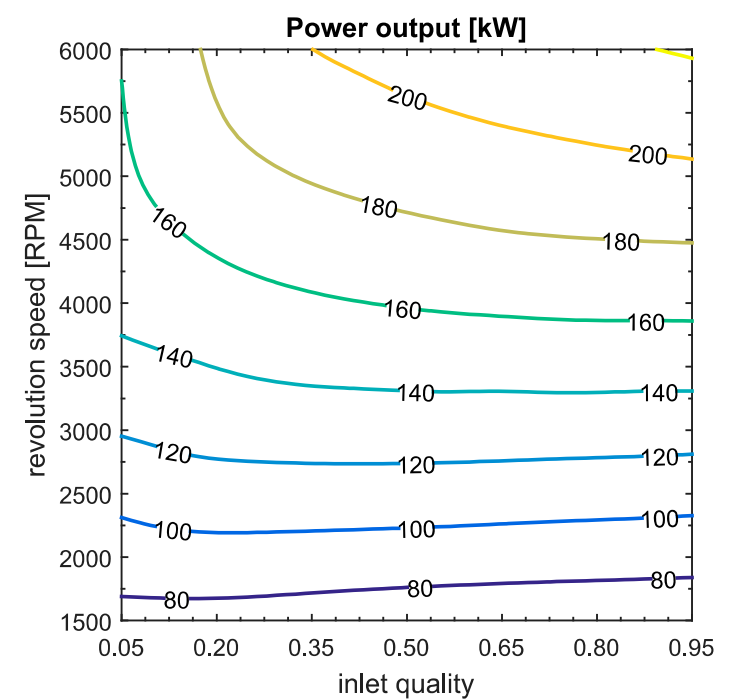

(b)

Figure 9. Twin-screw expander performance maps at constant manometric pressure ratio (Table 2): effects on the mass flow rate (a) and mechanical power output (b).

Figure 9 shows that, for a given expander speed, the specific power output increases with the fluid quality at the inlet of the expander. Indeed, even though Figure 9a reports a rather constant power output at speeds lower than 3500 RPM, the mass flow rate of the working fluid that expands in the machine decreases, as per Figure $9 \mathrm{~b}$. The reason for the trend observed in the power are due to two concurrent phenomena: (1) For the same inlet pressure, the higher the quality, the higher is the fluid specific enthalpy, thus leading to a greater specific enthalpy drop for the same manometric pressure ratio; (2) a higher inlet quality ensures a better filling of the expander cells that, in turn, minimizes the pressure drop which occur at the expander manifold [17]. This pre-expansion, which is usually not taken into account in cycle analysis of TFC systems, is a crucial factor. Indeed, thermodynamic studies assume saturated liquid conditions for the working fluid at the inlet of the expander. With reference to positive displacement machines, and particularly twin-screw expanders, due to their high revolution speeds, this saturated inlet state shall take place at the suction port of the machine and not at the inlet duct. Otherwise, especially if the inlet manifold is not properly designed, the claimed benefits of the flash expansion would be partly dissipated before the actual intake. This requirement introduces some challenges both from control and operational perspectives. Indeed, the control of the suction fluid quality is a challenging task that is still an open question for research. Should the fluid intake take place at liquid conditions, the non-compressible nature of the fluid might induce significant stresses to the expander. As can be noticed in Figure 9a, a small variation of quality for the same volumetric flow rate (i.e., revolution speed), implies a significant change in the density that reflects on the mass flow rate. For instance, at 3000 RPM, the mass flow rate doubles if the quality drops from 0.20 to 0.05 . 


\subsection{TFC System}

With reference to the model block diagram of the whole TFC unit shown in Figure 9, the boundary conditions used in the system simulations were pump and expander revolution speeds, the inlet conditions of the heat sink and heat source (mass flow rate, pressure and temperature), and the control valve opening. Table 3 shows the simulation results at the design point, which also served as reference for the off-design analysis. Compared to the initial layout presented in [23], where one third of the flow rate was sent to the pump through an additional connection on the receiver, in the one-dimensional model an additional condenser was considered. This explains the discrepancy in the cold water flow rate between Tables 2 and 3. Moreover, with respect to the TFC system performance resulting from the cycle analysis, the one-dimensional model predicts a lower power output ( $80 \mathrm{~kW}$ instead of $129 \mathrm{~kW}$ ) due to a slightly lower R245fa mass flow rate but mostly to a maximum cycle pressure that is equal to $6.4 \mathrm{bar}$ instead of 7.2 bar. This is due to the actual R245fa circuit properties that, for the same mass flow rate, is more permeable than the theoretical assumptions and, in turn, does not provide to build up the required pressure ratio in the circuit. In this simulation case, the effect of the control valve was discarded (valve fully opened).

Table 3. Results from the one-dimensional model at design point.

\begin{tabular}{cccc}
\hline & Hot Water & R245fa & Cold Water \\
\hline Mass flow rate $(\mathrm{kg} / \mathrm{s})$ & 7.84 & 24.65 & 130.30 \\
Inlet/Max pres (bar) & 4.0 & 6.4 & 3.0 \\
Outlet/Min pres (bar) & 3.9 & 1.1 & 2.7 \\
Inlet/Min temp $\left({ }^{\circ} \mathrm{C}\right)$ & 85 & 18 & 12 \\
Outlet/Max temp $\left({ }^{\circ} \mathrm{C}\right)$ & 25 & 63 & 17 \\
Pump speed $(\mathrm{RPM})$ & & 3000 & \\
Expanders speed (RPM) & & 4500 & \\
Expander isentropic eff. & & $74 \%$ & \\
Net power output $(\mathrm{kW})$ & & $80 \mathrm{~kW}$ & \\
Cycle thermal efficiency & & $4.3 \%$ & \\
\hline
\end{tabular}

In order to analyze the system behavior and performance during off-design conditions, the boundary conditions of the simulation have been varied with respect to the system reference point presented in Table 3. For each variable changed, the remaining ones have been maintained constant and equal to the design values. The effect of these variations has been assessed in terms of power output from both expanders, net cycle power output as well as cycle thermal efficiency. All the results reported are thermal powers, i.e., they are expressed as absolute enthalpy variations, without considering mechanical and electrical efficiencies of the machines.

Figure 10 shows the effect of expander and pump revolution speed variations. It is possible to notice that the expander substantially affects the system performance. Indeed, when the expander speed is increased from 3000 RPM to 6000 RPM, the system power output and overall cycle thermal efficiency drop from $88 \mathrm{~kW}$ to $60 \mathrm{~kW}$ and from $4.7 \%$ to $3.0 \%$ respectively (Figure 10a). The expander speed increase leads to a drop of the overall efficiency of the machine, with a consequent impact on the TFC unit performance. On the contrary, when the pump revolution speed is changed, minor effects can be noticed on the system power output and cycle thermal efficiency, which decrease from $88 \mathrm{~kW}$ to $72 \mathrm{~kW}$ and from $5.3 \%$ to $3.5 \%$ respectively when the pump speed is increased from 2500 RPM to 3500 RPM (Figure 10b). Due to the low hydraulic resistance of the R245fa loop, increasing the pump speed does not allow to increase considerably the maximum cycle pressure and thus the system performance.

An increase of the system performance can be noticed instead when the hot source inlet temperature and mass flow rate are increased. In the temperature case, the rise is steeper (Figure 11b), while for the mass flow rate one, smoother trends can be observed (Figure 11a). Indeed, an increment of the hot source inlet temperature from $75^{\circ} \mathrm{C}$ to $95^{\circ} \mathrm{C}$ increases the net power output from $60 \mathrm{~kW}$ up to $116 \mathrm{~kW}$ 
and the cycle thermal efficiency from $3.7 \%$ up to $5.2 \%$ (Figure 11b). For the same percentage change of the hot source mass flow rate, the power output and the thermal efficiency of the TFC unit rise from $63 \mathrm{~kW}$ to $97 \mathrm{~kW}$ and from $4.2 \%$ up to $4.7 \%$ respectively (Figure 11a). This performance increase is not due to an augmented expansion ratio across the expander but rather to an increase of the refrigerant quality at the inlet of the machine, which rises from 0.10 up to 0.16 and from 0.11 up to 0.14 when the temperature and mass flow rate of the hot source are increased from $75^{\circ} \mathrm{C}$ to $95^{\circ} \mathrm{C}$ and from $5.84 \mathrm{~kg} / \mathrm{s}$ to $10.19 \mathrm{~kg} / \mathrm{s}$, respectively.

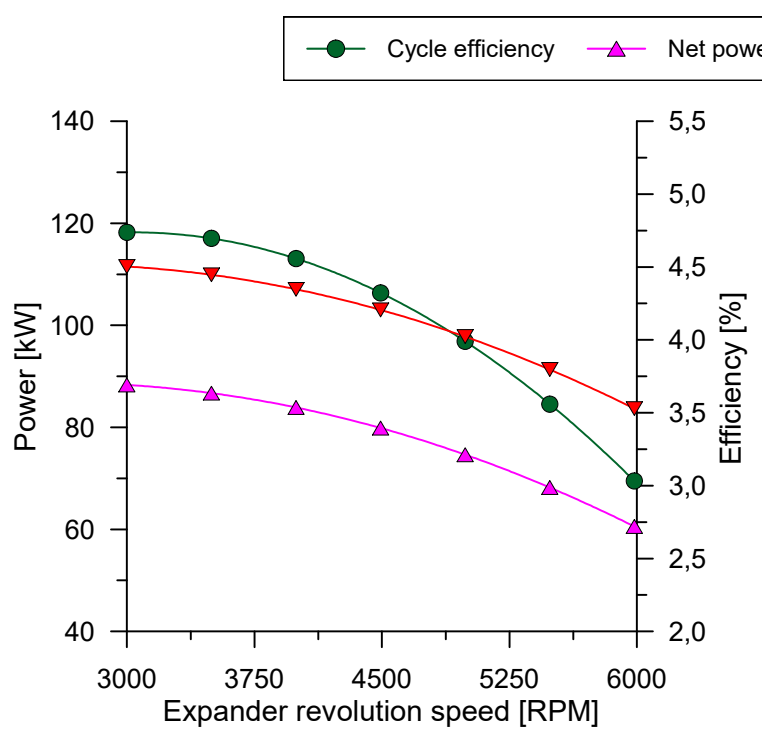

(a)

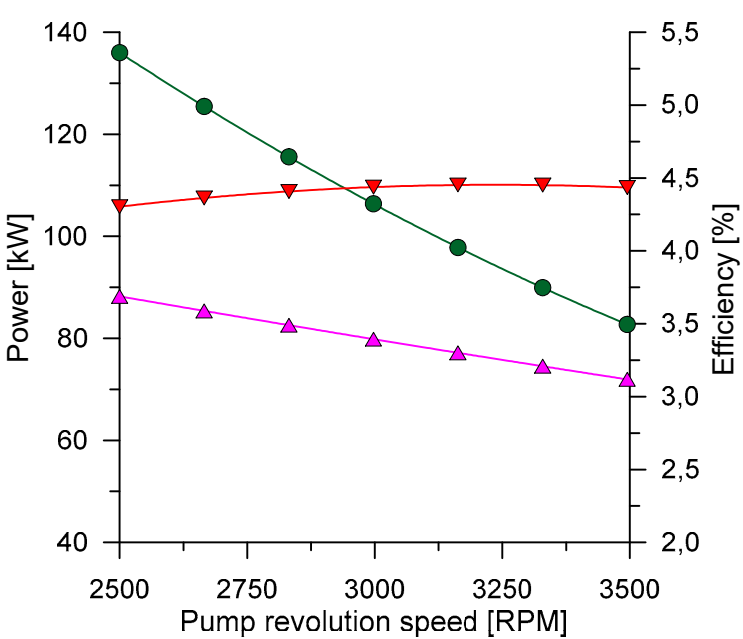

(b)

Figure 10. Results of the system and expander performance in on and off-design conditions varying: (a) the expander revolution speed and (b) the pump revolution speed.

\section{Cycle efficiency $\longrightarrow$ Net power output $\rightarrow-$ Expander power output}

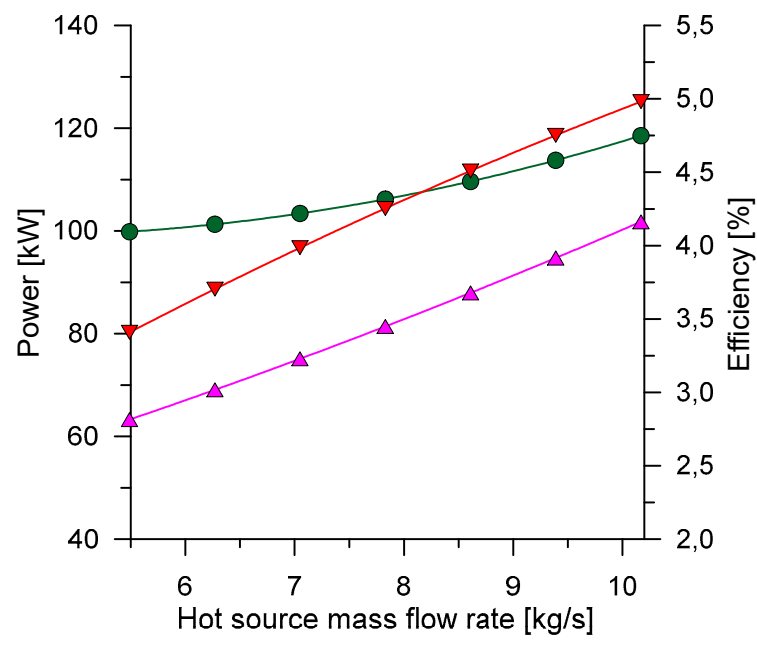

(a)

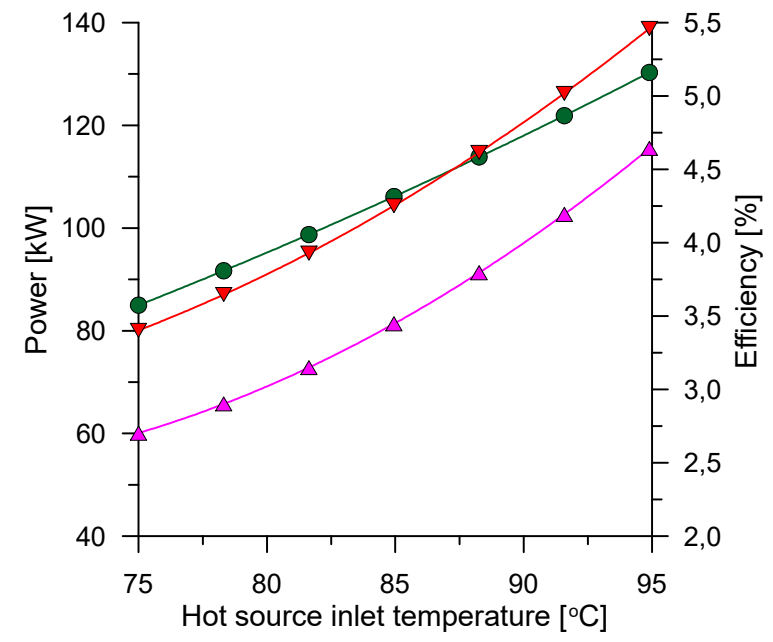

(b)

Figure 11. Results of the system and expander performance in on and off-design conditions varying: (a) the hot source mass flow rate and (b) the hot source inlet temperature. 
After the off-design analysis, a series of simulations have been carried out to assess how the valve opening affects the system and expander performance, considering as well its effect on the expander isentropic efficiency and the refrigerant quality at the inlet of the machine. Therefore, the valve area has been varied from the $9 \%$ (valve fully closed) to $100 \%$ (valve fully open) of the adjacent pipes flow area, while the other variables of the system were set at their reference value (Table 3). The results of the analysis are shown in Figure 12. It can be seen that the closing of the valve does not produce any sensible effect on the expander isentropic efficiency, which remains almost constant around the value of $74 \%$, while it affects the working fluid quality at the expander inlet, which goes from 0.11 when the valve is fully opened up to 0.16 (Figure 12b) when it is closed until its maximum position (9\% control valve opening).

The increment of refrigerant quality is beneficial for the power generated by the expander, since it ranges from $105 \mathrm{~kW}$ up to $123 \mathrm{~kW}$. This output increment consequently leads also to a higher net power output and the cycle thermal efficiency, which increase from $80 \mathrm{~kW}$ to $100 \mathrm{~kW}$ and from $4.3 \%$ to $5.2 \%$ respectively when the valve is closed (Figure 12a). The minima noticeable in Figure 12 can be explained by the not linear trend between the valve opening area reduction and the consequent pressure drop introduced in the circuit. For small area reductions, the pressure drops introduced by the valve are not significant and do not affect considerably the refrigerant quality at the expander inlet. Reducing further the control valve area increases the dissipative action with a consequently more pronounced effect on the refrigerant conditions at the inlet of the expanders.

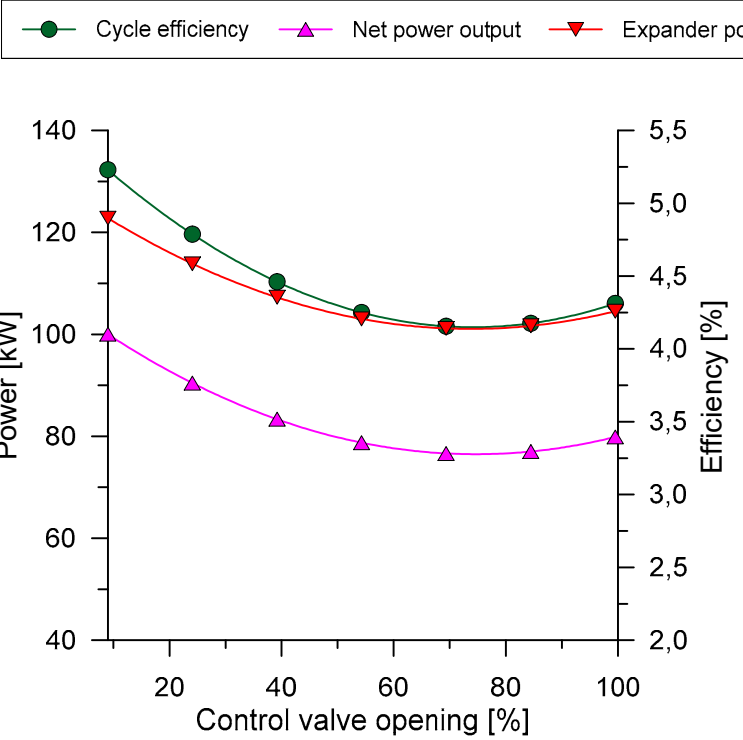

(a)

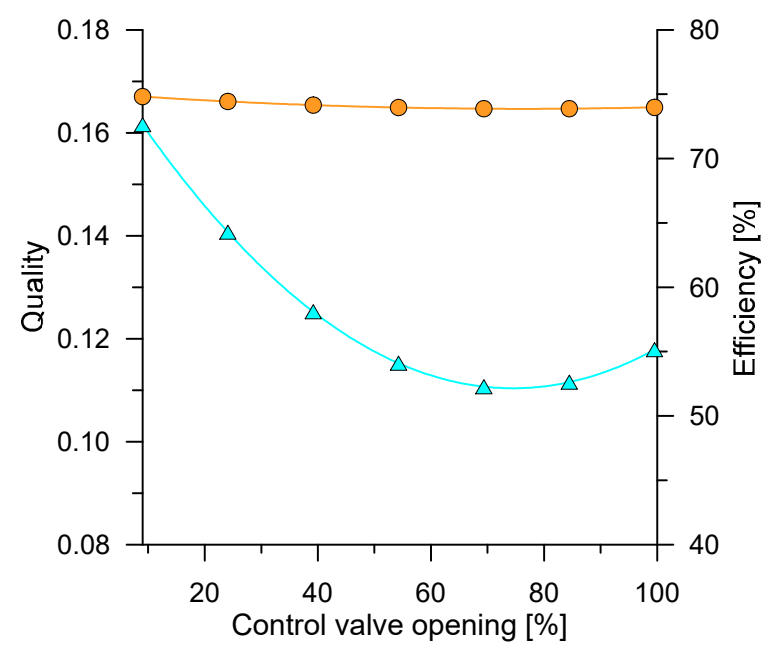

(b)

Figure 12. Results obtained by the off-design model simulations varying the control valve opening area: (a) Cycle thermal efficiency, net and expander power output; (b) expander isentropic efficiency and refrigerant quality at the inlet of the machine. 


\section{Conclusions}

This paper presented a one-dimensional modelling methodology for a low-grade heat to power system based on a Trilateral Flash Cycle (TFC) and equipped with two-phase positive displacement twin-screw expanders, which require information of the chamber volume and leakage areas from an external geometrical pre-processor.

The standalone model of the twin-screw expander was used to generate performance maps of the machine that functioned as input data for the TFC system simulations. The maps show that, for a given expander speed, the specific power output increased with the fluid quality at the inlet of the expander. For instance, at $3000 \mathrm{RPM}$, the specific power output at a quality of 0.05 was $4 \mathrm{~kW} /(\mathrm{kg} / \mathrm{s})$ while at a quality of 0.40 the specific power reached $12 \mathrm{~kW} /(\mathrm{kg} / \mathrm{s})$. This was due an increase of the specific enthalpy at higher vapor fractions but also to a better filling of the expander cells that minimized the pressure drop which occur at the expander manifold. The pre-expansion at the inlet manifold is, in fact, a key phenomenon that leads to a deviation from a theoretical perspective of the Trilateral Flash Cycle, where the saturated liquid conditions at the end of the heat recovery are also the ones at the beginning of the actual expansion process.

Compared to the cycle analysis, the one-dimensional model of the TFC system reported lower performance at design conditions, namely $80 \mathrm{~kW}$ instead of $129 \mathrm{~kW}$ and $4.3 \%$ instead of $6.4 \%$. This discrepancy is due to a lower maximum cycle pressure achievable in the R245fa loop.

The performance of the TFC system was investigated at off-design conditions. In particular, the sensitivity analysis considered pump and expander speeds, hot source mass flow rate and temperature, and the opening of a valve upstream the expanders as exploratory variables. The most significant variable for the TFC system performance was the expander revolution speed. Indeed, when the expander speed is increased from 3000 RPM to 6000 RPM, the system power output and overall cycle thermal efficiency drop from $88 \mathrm{~kW}$ to $60 \mathrm{~kW}$ and from $4.7 \%$ to $3.0 \%$ respectively. Another important process parameter for the TFC system performance was identified in the hot source temperature. However, unlike the expander speed, this parameter relates to the topping industrial process. As such, it cannot be used to control the unit.

Author Contributions: Conceptualization, J.M. and S.T.; Funding acquisition, J.M. and S.T.; Investigation, G.B. and M.M.; Methodology, G.B.; Resources, S.K.; Supervision, S.T.; Writing - original draft, G.B. and M.M.; Writing review \& editing, S.K., J.M. and S.T.

Funding: The authors would like to acknowledge funding for this project from: (i) Innovate UK (Project No. 61995-431253, (ii) Engineering and Physical Sciences Research Council UK (EPSRC), Grant No. EP/P510294/1; iii) Research Councils UK (RCUK), Grant No. EP/K011820/1.

Acknowledgments: The authors would also like to acknowledge support and contributions from the following organizations: Spirax Sarco Engineering PLC, Howden Compressors Ltd., Artic Circle Ltd., Cooper Tires Ltd. and Industrial Power Units Ltd. The manuscript reports all the relevant data to support the understanding of the results. More detailed information and data, if required, can be obtained by contacting the corresponding author of the paper.

Conflicts of Interest: The authors declare no conflict of interest. The funders had no role in the design of the study; in the collection, analyses, or interpretation of data; in the writing of the manuscript, or in the decision to publish the results. 


\section{Abbreviations}

$\begin{array}{ll}e & \text { specific total internal energy }\left(\mathrm{J} \mathrm{kg}^{-1}\right) \\ m & \text { mass }(\mathrm{kg}) \\ \dot{m} & \text { mass flow rate }\left(\mathrm{kg} \mathrm{s}^{-1}\right) \\ p & \text { pressure }(\mathrm{Pa}) \\ t & \text { time }(\mathrm{s}) \\ u & \text { velocity at the boundary }\left(\mathrm{m} \mathrm{s}^{-1}\right) \\ A & \text { area }\left(\mathrm{m}^{2}\right) \\ B & \text { total number of boundaries } \\ C_{f} & \text { Fanning friction factor } \\ D & (\text { equivalent }) \text { diameter }(\mathrm{m}) \\ H & \text { heat transfer coefficient }\left(\mathrm{W} \mathrm{m}^{-2} \mathrm{~K}^{-1}\right) \\ K_{p} & \text { pressure loss coefficient } \\ L & \text { length }(\mathrm{m}) \\ T & \text { temperature }(\mathrm{K}) \\ V & \text { volume }\left(\mathrm{m}^{3}\right) \\ Z & \text { number of cells } \\ \alpha & \text { crank angle }\left({ }^{\circ}\right) \\ \gamma & \text { ratio of specific heats } \\ \zeta & \text { spatial reference }(\mathrm{m}) \\ \rho & \text { density }\left(\mathrm{kg} \mathrm{m}^{-3}\right) \\ \omega & \text { revolution speed }(\mathrm{RPM}) \\ \Delta \alpha & \text { angular cycle duration }\left({ }^{\circ}\right) \\ s & \text { heat transfer surface } \\ \text { sim } & \text { simulated } \\ & \end{array}$

\section{References}

1. Tu, J.; Yeoh, G.H.; Liu, C. Computational Fluid Dynamics: A practical Approach; Butterworth-Heinemann: Oxford, UK, 2018.

2. Patel, K.S.; Patel, S.B.; Patel, U.B.; Ahuja, A.P. CFD Analysis of an Aerofoil. Int. J. Eng. Res. 2014, 3, $154-158$. [CrossRef]

3. Rizzi, A. Modeling and simulating aircraft stability and control-The SimSAC project. Prog. Aerosp. Sci. 2011, 47, 573-588. [CrossRef]

4. Bianchi, G.; Rane, S.; Kovacevic, A.; Cipollone, R.; Murgia, S.; Contaldi, G. Development of a General Numerical Methodology for CFD Analyses in Sliding Vane Machines and Application on a Mid-Size Oil Injected Air Compressor. In Proceedings of the International Compressor Engineering Conference at Purdue University, West-Lafayette, IN, USA, 11-14 July 2016.

5. Quoilin, S.; Broek, M.V.D.; Declaye, S.; Dewallef, P.; Lemort, V. Techno-economic survey of Organic Rankine Cycle (ORC) systems. Renew. Sustain. Energy Rev. 2013, 22, 168-186. [CrossRef]

6. Tocci, L.; Pal, T.; Pesmazoglou, I.; Franchetti, B.; Tocci, L.; Pal, T.; Pesmazoglou, I.; Franchetti, B. Small Scale Organic Rankine Cycle (ORC): A Techno-Economic Review. Energies 2017, 10, 413. [CrossRef]

7. Fischer, J. Comparison of trilateral cycles and organic Rankine cycles. Energy 2011, 36, 6208-6219. [CrossRef]

8. Lai, N.A.; Fischer, J. Efficiencies of power flash cycles. Energy 2012, 44, 1017-1027. [CrossRef]

9. Qi, Y.; Yu, Y. Thermodynamic Simulation on the Performance of Twin Screw Expander Applied in Geothermal Power Generation. Energies 2016, 9, 694. [CrossRef]

10. Fleming, J.S.; Tang, Y. The Analysis of Leakage in a Twin Screw Compressor and its Application to Performance Improvement, Proceedings of the Institution of Mechanical Engineers. Part E J. Process Mech. Eng. 1995, 209, 125-136. [CrossRef]

11. Kanno, H.; Shikazono, N. Experimental study on two-phase adiabatic expansion in a reciprocating expander with intake and exhaust processes. Int. J. Heat Mass Transf. 2016, 102, 1004-1011. [CrossRef]

12. Papes, I.; DeGroote, J.; Vierendeels, J. New insights in twin screw expander performance for small scale ORC systems from 3D CFD analysis. Appl. Therm. Eng. 2015, 91, 535-546. [CrossRef] 
13. Stosic, N.; Smith, I.; Kovacevic, A. Screw Compressors: Mathematical Modelling and Performance Calculation; Springer Science \& Business Media: Berlin, Germany, 2005.

14. Gamma Technologies. GT-SUITE-Flow Theory Manual; Gamma Technologies: Westmont, IL, USA, 2019.

15. Lemmon, E.W.; Huber, M.L.; Mclinden, M.O. NIST Reference Fluid Thermodynamic and Transport Properties-REFPROP User's Guide; National Institute of Standards and Technology: Gaithersburg, MD, USA, 2019.

16. Marchionni, M.; Bianchi, G.; Karvountzis-Kontakiotis, A.; Pesiridis, A.; Tassou, S.A. Dynamic modeling and optimization of an ORC unit equipped with plate heat exchangers and turbomachines. Energy Procedia. 2017, 129, 224-231. [CrossRef]

17. Bianchi, G.; Kennedy, S.; Zaher, O.; Tassou, S.A.; Miller, J.; Jouhara, H. Numerical modeling of a two-phase twin-screw expander for Trilateral Flash Cycle applications. Int. J. Refrig. 2018, 88, 248-259. [CrossRef]

18. Brkić, D. Review of explicit approximations to the Colebrook relation for flow friction. J. Pet. Sci. Eng. 2011, 77, 34-48. [CrossRef]

19. Dittus, F.; Boelter, L. Heat Transfer in Automobile Radiators of the Tubular Type; University of California Publications: Berkeley, CA, USA, 1930.

20. Yan, Y.Y.; Lio, H.C.; Lin, T.F. Condensation heat transfer and pressure drop of refrigerant R-134a in a plate heat exchanger. Int. J. Heat Mass Transf. 1999, 42, 993-1006. [CrossRef]

21. Donowski, V.D.; Kandlikar, S.G. Correlating Evaporation Heat Transfer Coefficient of Refrigerant R-134a in a Plate Heat Exchanger. In Proceedings of the Engineering Foundation Conference on Pool and Flow Boiling, Anchorage, AK, USA, 30 April-5 May2000; pp. 1-18.

22. Zhang, J.; Kærn, M.R.; Ommen, T.; Elmegaard, B.; Haglind, F. Condensation heat transfer and pressure drop characteristics of R134a, R1234ze(E), R245fa and R1233zd(E) in a plate heat exchanger. Int. J. Heat Mass Transf. 2019, 128, 136-149. [CrossRef]

23. Bianchi, G.; McGinty, R.; Oliver, D.; Brightman, D.; Zaher, O.; Tassou, S.A.; Miller, J.; Jouhara, H. Development and analysis of a packaged Trilateral Flash Cycle system for low grade heat to power conversion applications. Therm. Sci. Eng. Prog. 2017, 4, 113-121. [CrossRef]

(C) 2019 by the authors. Licensee MDPI, Basel, Switzerland. This article is an open access article distributed under the terms and conditions of the Creative Commons Attribution (CC BY) license (http://creativecommons.org/licenses/by/4.0/). 